\title{
Volatile Flavor Components of Cooked Rice
}

\author{
Izumi Yajima, Tetsuya Yanal, Mikio NaKamura, \\ Hidemasa Sakakibara and Tsutomu HabU
}

\author{
Kawasaki Research Laboratories, T. Hasegawa Co., Ltd., Kawasaki, Japan
}

Received January 17, 1978

\begin{abstract}
Volatile flavor components of cooked rice were studied. Steam distillate of cooked rice was extracted with methylene chloride and the extract was separated into four fractions: acidic, weak acidic, basic and neutral fractions. The neutral fraction was further separated into hydrocarbons and oxygenated compounds by column chromatography. All fractions were analyzed by a combination of glass capillary gas chromatography and mass spectrometry.

One hundred constituents, including 13 hydrocarbons, 13 alcohols, 16 aldehydes, 14 ketones, 14 acids, eight esters, five phenols, three pyridines, six pyrazines, and eight other compounds, were identified. Of these, 92 were newly identified volatile flavor components of cooked rice.
\end{abstract}

Many studies have been carried out on rice, especially on its nutritional and chemical compositions, but few have focused on the volatile flavor components of cooked rice. Obata and Tanaka ${ }^{1}$ identified hydrogen sulfide, ammonia and carbon dioxide in the vapors of cooked rice, and Yasumatsu et al. ${ }^{21}$ found volatile carbonyl compounds such as acetaldehyde, propanal (or acetone), 2-butanone, pentanal and hexanal and discussed the mechanism of their formation. Ayano and Furuhashi ${ }^{3}$ also investigated the carbonyl compounds from cooked rice and reported them to be mainly acetaldehyde, pentanal and hexanal. Only a few volatile compounds have thus been reported for cooked rice. This investigation was undertaken to identify additional volatile flavor components in cooked rice.

\section{MATERIALS AND METHODS}

\section{Materials.}

The ric eused was Koshihikari harvested in Niigata Prefecture. It was newly hulled and $80 \%$ polished.

\section{Methods}

a) Steam distillation of cooked rice. A mixture of $6 \mathrm{~kg}$ of rice, washed with water, and $6.5 \mathrm{~kg}$ of water was placed in a 50-liter closed stainless stell vessel illustrated in Fig. 1. The mixture was heated to and maintained at $120^{\circ} \mathrm{C}$ for $40 \mathrm{~min}$ to cook the rice. This cooked rice was immediately steam distilled by intro- ducing steam into the same vessel, resulting in $3 \mathrm{~kg}$ of distillate containing volatile flavor components.

This process was repeated eight times, giving $23.5 \mathrm{~kg}$ of distillate from $48 \mathrm{~kg}$ of rice.

b) Extraction of flavor components. The distillate was extracted three times with 2.5 liters of methylene chloride and the extract was concentrated to a volume of $600 \mathrm{ml}$. Of this $600 \mathrm{ml}$ of aroma concentrate, $100 \mathrm{ml}$ was further concentrated to approximately $0.1 \mathrm{ml}$ for analysis by gas chromatography (GC) and the remaining $500 \mathrm{ml}$ was fractionated by the following method.

c) Fractionation of aroma concentrate. As shown in Fig. 2, aroma concentrate was separated into four fractions: acidic, weak acidic, basic and neutral. Each fraction was concentrated to approximately $0.1 \mathrm{ml}$.

The neutral fraction was further subjected to column chromatography in order to separate hydrocarbons from oxygenated compounds. It was placed at the top of a $10 \mathrm{~mm} \times 50 \mathrm{~mm}$ column packed with silica gel and eluted with $50 \mathrm{ml}$ of $n$-pentane, followed by $50 \mathrm{ml}$ of ethyl ether and finally $50 \mathrm{ml}$ of methanol. Each fraction was concentrated to approximately $0.1 \mathrm{ml}$.

All these fractions were analyzed by $\mathrm{GC}$ and gas chromatography-mass spectrometry (GC-MS), with the exception of the acidic fraction which was analyzed after methylation.

d) GC conditions. A Hitachi Model 163 gas chromatograph with a flame ionization detector and a $0.28 \mathrm{~mm}$ i.d. $\times 50 \mathrm{~m}$ glass capillary column coated with PEG $20 \mathrm{M}$ was used. The column temperature was programmed from $60^{\circ} \mathrm{C}$ to $190^{\circ} \mathrm{C}$ at a rate of $2^{\circ} \mathrm{C} / \mathrm{min}$ and the flow rate of helium carrier gas was $1 \mathrm{ml} / \mathrm{min}$. 


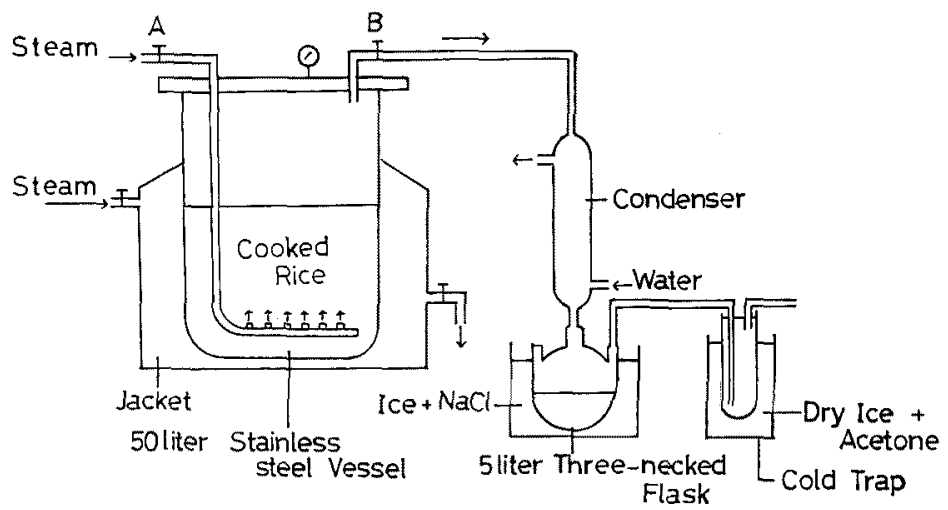

FIG. 1. Apparatus for Steam Distillation of Cooked Rice.

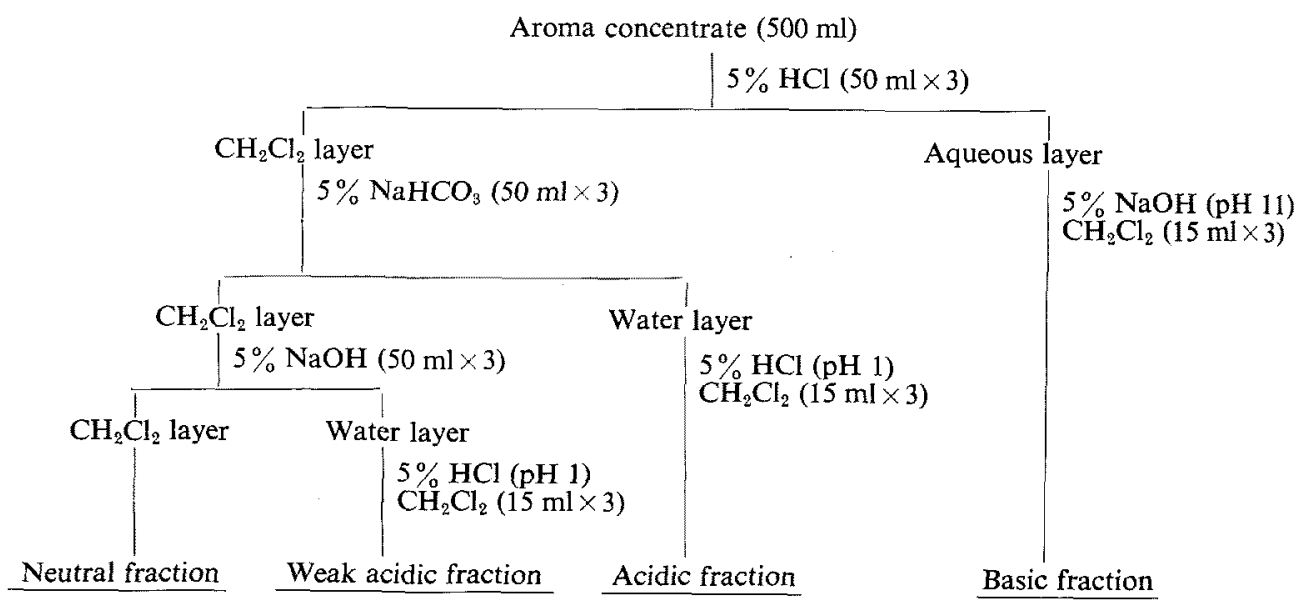

FIG. 2. Fractionation of Aroma Concentrate of Cooked Rice.

e) GC-MS conditions. A Hitachi Model RMU6MG mass spectrometer was used. GC column conditions were as described above for GC. Other operating parameters were as follows: column oven temperature and programmed rate of gas chromatograph, $50^{\circ} \mathrm{C}$ to $170^{\circ} \mathrm{C}$ at a rate of $2^{\circ} \mathrm{C} / \mathrm{min}$; ionizing voltage, $70 \mathrm{eV}$; accelerating voltage, $3200 \mathrm{v}$; ion source temperature, $200^{\circ} \mathrm{C}$.

\section{RESULTS AND DISCUSSION}

Yields of flavor compounds obtained from each fraction are listed in Table $\mathrm{I}$. The total flavor compound yield is $230 \mathrm{mg}$, which is equivalent to only $4.8 \mathrm{ppm}$ of the wieght of the rice used. It was found from this that the cooked rice contained only small amounts of flavor compounds.

Also, as can be seen from Table I, weakly acidic and neutral oxygenated compounds
Table I. Yields of Flavor Compounds OF COOKED RICE

\begin{tabular}{lr}
\hline \multicolumn{1}{c}{ Fractions } & Yields \\
\hline Total amounts of flavor compounds & $230 \mathrm{mg}(4.8 \mathrm{ppm})$ \\
\hline Acidic fraction & $145 \mathrm{mg}$ \\
Weak acidic Fr. & $141 \mathrm{mg}$ \\
Acidic Fr. & \multicolumn{2}{c}{$4 \mathrm{mg}$} \\
\hline Basic fraction & $2 \mathrm{mg}$ \\
\hline Neutral fraction & $73 \mathrm{mg}$ \\
Hydrocarbon Fr. & \multicolumn{2}{c}{$7 \mathrm{mg}$} \\
Oxygenated compounds Fr. & $61 \mathrm{mg}$ \\
\hline
\end{tabular}

comprise approximately $90 \%$ of the total flavor compounds, and therefore it can be assumed that the volatile flavor components of cooked rice are mainly phenols, higher acids and neutral oxygenated compounds such as alcohols, aldehydes, ketones and esters.

A gas chromatogram of aroma concentrate 


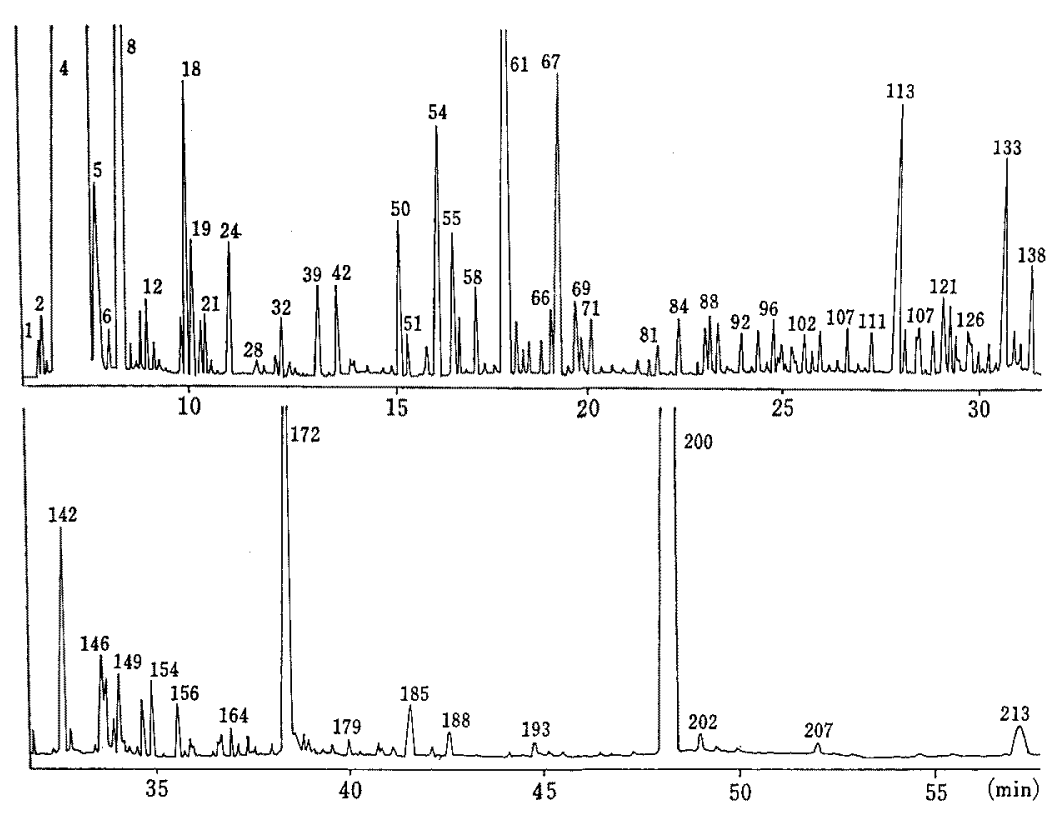

Frg. 3. Gas Chromatogram of Aroma Concentrate of Cooked Rice.

of cooked rice is shown in Fig. 3. The chromatogram indicates the presence of over 210 compounds, of which 100 were identified. Identifications were made by comparing and matching the mass spectra and GC retention times of the unknown compounds with those of authentic compounds.

The 100 compounds thus identified from cooked rice are shown in Table II. Of these, 92 were identified in cooked rice for the first time, though some are known to be volatiles of unprocessed rice ${ }^{4}$ and rice bran..$^{51}$

Of the acidic compounds other than higher fatty acids, 4-vinylphenol and 4-vinylguaiacol were the major components. These phenols are considered to be formed by thermal decomposition of the $p$-coumaric and ferulic acid existing in rice during cooking and/or steam distillation. ${ }^{6}$,

Most of the basic compounds identified, though present in small quantities, were pyridines and pyrazines which are thought to have been developed by Maillard reaction.

The major neutral oxygenated compounds were alcohols and aldehydes such as $n$-butanol, n-pentanol, 2-ethylhexanol, $n$-hexanal, n-non-
Table II. Volatile Flavor Compounds IDENTIFIED FROM COOKED RICE

\begin{aligned} \hline Peak No. & \multicolumn{1}{c}{ Compounds } \\ \hline 13 & Hydrocarbons \\ 21 & Xylene \\ 29 & Limonene \\ 31 & -Cymene \\ 67 & Pentadecane \\ 81 & Hexadecane \\ 96 & Naphthalene \\ 104 & Heptadecane \\ 119 & Methylnaphthalene \\ 121 & Octadecane \\ 138 & Nonadecane \\ 149 & Eicosane \\ 163 & Heneicosane \\ & Alcohols \\ 12 & Butanol-1 \\ 20 & 3-Methyl-1-butanol \\ 24 & Pentanol-1 \\ 42 & Hexanol-1 \\ $55^{a} &$ 2-Ethyl-4-methylpentan-1-ol \\ 60 & 1-Octen-3-ol \\ 61 & 2-Ethylhexanol \\ 70 & Linalool \\ 71 & Octanol-1 \\ 123 & Benzyl alcohol \\ 130 & 2-Phenylethyl alcohol \\ 152 & Nerolidol \\ & \end{aligned}




\begin{tabular}{|c|c|}
\hline Peak No. & Compounds \\
\hline 188 & $\begin{array}{l}\text { Pentadecanol-1 } \\
\text { Aldehydes }\end{array}$ \\
\hline $5^{b}$ & Pentanal \\
\hline $8^{b}$ & Hexanal \\
\hline 17 & Heptanal \\
\hline 22 & trans-2-Hexenal \\
\hline 32 & Octanal \\
\hline 39 & trans-2-Heptenal \\
\hline 50 & Nonanal \\
\hline 54 & trans-2-Octenal \\
\hline 59 & Furfural \\
\hline 62 & Decanal \\
\hline 66 & Benzaldehyde \\
\hline 69 & trans-2-Nonenal \\
\hline 86 & Phenylacetaldehyde \\
\hline 89 & trans-2-Decenal \\
\hline $107^{a}$ & trans-2-cis-4-Decadienal \\
\hline 113 & $\begin{array}{l}\text { trans-2-trans-4-Decadienal } \\
\text { Ketones }\end{array}$ \\
\hline 9 & trans-3-Penten-2-one \\
\hline 19 & 2-Heptanone \\
\hline 27 & 3-Octanone \\
\hline 31 & 2-Octanone \\
\hline 40 & 6-Methylhept-5-en-2-one \\
\hline 46 & 2-Nonanone \\
\hline 74 & Isophorone \\
\hline 78 & 6-Methylhepta-3,5-dien-2-one \\
\hline 81 & 2-Undecanone \\
\hline 88 & Acetophenone \\
\hline 146 & 2-Pentadecanone \\
\hline 162 & $6,10,14$-Trimethyl pentadecan-2-one \\
\hline 179 & 2-Heptadecanone \\
\hline 212 & $\begin{array}{l}\text { 2-Nonadecanone } \\
\text { Esters }\end{array}$ \\
\hline 100 & Ethyl benzoate \\
\hline 122 & Geranyl acetate \\
\hline 153 & Ethyl myristate \\
\hline 178 & Methyl palmitate \\
\hline 182 & $\begin{array}{l}\text { Ethyl palmitate } \\
\text { Ethyl stearate } \\
\text { Ethyl oleate } \\
\text { Ethyl linoleate } \\
\text { Pyridines }\end{array}$ \\
\hline 18 & $\overline{\text { Pyridine }}$ \\
\hline 26 & 2-Methylpyridine \\
\hline 33 & $\begin{array}{l}\text { 3-Methylpyridine } \\
\text { Pyrazines }\end{array}$ \\
\hline 25 & Pyrazine \\
\hline 28 & 2-Methylpyrazine \\
\hline 34 & 2,5-Dimethylpyrazine \\
\hline 37 & 2,6-Dimethylpyrazine \\
\hline 43 & 2,3-Dimethylpyrazine \\
\hline 48 & $\begin{array}{l}\text { 2,3,5-Trimethylpyrazine } \\
\text { Phenols }\end{array}$ \\
\hline 114 & $\overline{\text { Guaiacol }}$ \\
\hline
\end{tabular}

\begin{tabular}{rl}
\hline Peak No. & \multicolumn{1}{c}{ Compounds } \\
\hline 133 & Phenol \\
154 & $p$-Cresol \\
172 & 4-Vinylguaiacol \\
200 & 4-Vinylphenol \\
& Acids \\
107 & Caproic acid \\
147 & Caprylic acid \\
166 & Nonanoic acid \\
185 & Capric acid \\
213 & Lauric acid \\
& Tridecanoic acid \\
$b$ & Myristic acid \\
& Pentadecanoic acid \\
$b$ & Palmitic acid \\
$a$ & Hexadecenoic acid \\
$b$ & Stearic acid \\
$b$ & Oleic acid \\
$b$ & Linoleic acid \\
$b$ & Linolenic acid \\
& Miscillaneous \\
103 & Aniline \\
133 & B.H.T. \\
134 & Quinoline \\
135 & Benzothiazol \\
163 & 2,3-Dimethyl-2-nonen-4-olide \\
207 & Indole \\
& Diethyl phthalate \\
& Dibutyl phthalate \\
\hline Tentatively identified. \\
Previously reported. \\
\hline
\end{tabular}

anal and trans-2-octenal. Most of ketones, though minor constituents, were identified as methyl ketones.

It is generally recognized that alcohols are formed by oxidation of lipids, aldehydes by oxidation of certain amino acids and fatty acids, and methyl ketones by beta-oxidation of fatty acids during heating.

These oxygenated compounds seem to be the major contributors to the flavor of cooked rice, but none of the individual compounds were found to have the characteristic odor of cooked rice.

Further detailed experiments are necessary.

\section{REFERENCES}

1) Y. Obata and H. Tanaka, Agric. Biol. Chem., 29, 191 (1965).

2) K. Yasumatsu, S. Moritaka and S. Wada, ibid, 30, 478 (1966). 
3) Y. Ayano and T. Furuhashi, Chiba Daigaku Engeigakubu Gakujutsu Hokoku, 18, 53 (1970).

4) R. W. Bullard and G. Holguin, J. Agric. Food Chem., 25, 99 (1977).

5) M. Fujimaki, T. Tsugita and T. Kurata, Abstracts Papers, Annual Meeting of Agricultural Chemical Society of Japan, Sapporo, 1975, p.
257.; idem, ibid., Kyoto, 1976, p. 392; idem, ibid., Yokohama, 1977, p. 330; idem, Agric. Biol. Chem., 41, 1721 (1977).

6) R. D. Steinke and M. C. Paulson, J. Agric. Food Chem., 12, 381 (1964); W. Fiddler, W. E. Parker, A. E. Wasserman and R. C. Doerr, ibid., 15, 757 (1967). 